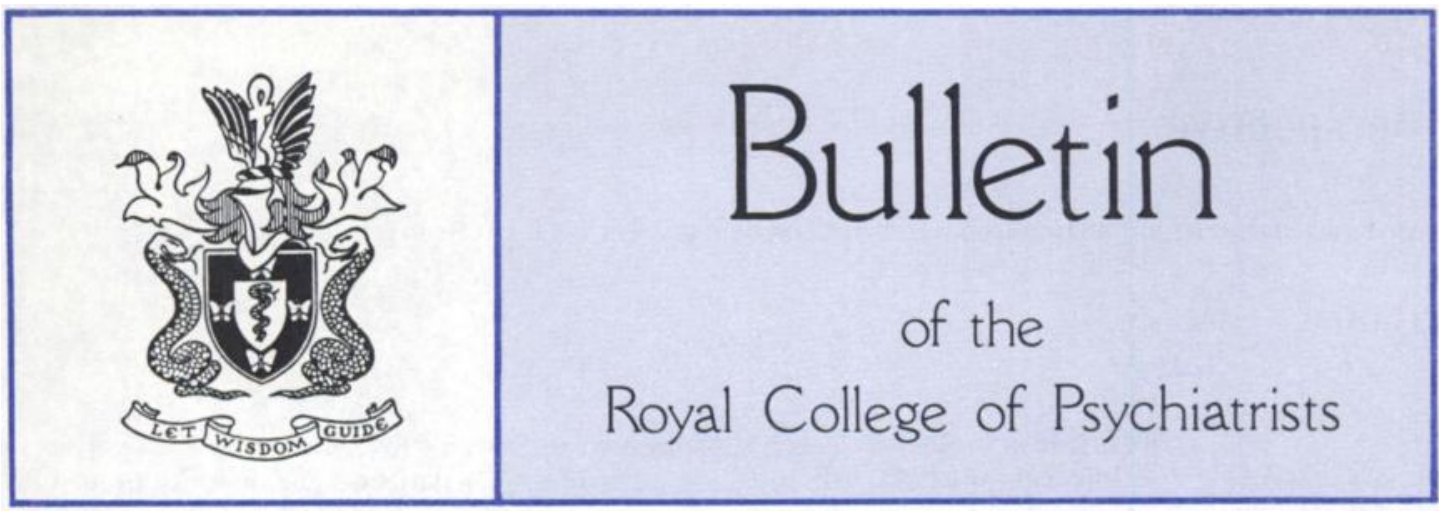

\title{
Contents
}

Perspective: Thomas Freeman

Articles

Conflicts and context in managing the closure of a large psychiatric hospital. Lorna McKee Phenomenology and the price of beans. Dennis Flannery

Intensive psychotherapy with in-patients at Chestnut Lodge Hospital. Marco C. Chiesa

The use of the EEG in clinical psychiatry. P.C.W. Bowie, A. Y. Beaini and A. A. da Costa

The medicine of misery: a personal account. Lynne Jones

A casualty psychiatric clinic at the Royal Liverpool Hospital. Hadrian N. Ball and Michael

I. Levi

Comment

Co-ordinated aftercare for schizophrenia-A report of a pilot project. R. G. McCreadie 335

Correspondence

The College

Spring Quarterly Meeting 1988

Distinction awards in psychiatry $\quad 342$

The 1987 North West Division trainees' day. C. F. Sullivan and R. E. Polley 343

Obituary

Reviews

Miscellany $\quad 349$

$\begin{array}{ll}\text { Forthcoming events } & 350\end{array}$

\section{Notice to contributors}

The Editors welcome articles of general interest to psychiatrists. Two thousand words is a good length; however, longer articles will be considered. Tables, diagrams and extended references should generally not be included. Please submit three copies, typed double-spaced. Correspondence on subjects of topical interest is also welcome. Contributions are accepted for publication on the condition that their substance has not been published or submitted for publication elsewhere. The views expressed in articles published in the Bulletin (except official College material) are the author's own and do not necessarily represent College policy. 